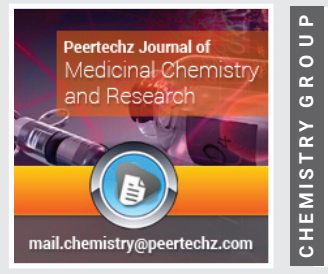

\title{
Selenium nanoparticles: Small is the new big: Mini review
}

\section{Jolly Jolly ${ }^{1}$, Mohd Ahmar Rauf ${ }^{2}$ and Zeeshan Ahmad ${ }^{2 *}$}

Department of Biochemistry, Aligarh Muslim University, Aligarh, Industrial and System Engineering -

Wayne State University, Detroit, MI, USA
Received: 26 June, 2020

Accepted: 21 July, 2020

Published: 22 July, 2020

*Corresponding author: Zeeshan Ahmad, Department of Biochemistry, Aligarh Muslim University, Aligarh, Industrial and System Engineering - Wayne State University, Detroit, MI, USA, E-mail: ahmarrauf3@gmail. com,Zeeshanapro@gmail.com

https://www.peertechz.com

Check for updates

\begin{abstract}
Nanotechnology is the study of developing peculiar particles (1-100 nanometres $(\mathrm{nm})$ ) of matter at an atomic, molecular, and supramolecular scale. These nanoparticles possess unique properties such as large surface area, fewer side effects, bioavailability, decrease the toxicity, and prolonged drug release. Some inorganic metals nanoparticles like $\mathrm{Ti}, \mathrm{Se}, \mathrm{Zn}, \mathrm{Ag}, \mathrm{Ce}, \mathrm{Au}$, and Fe play possess antonymous bioactivities. Selenium is the essential trace element and essential micronutrient in the biological system. There are 25 selenoproteins in the human body possessing oxidoreductase activity; therefore, regulating the physiological redox balance in the organs system. Selenium nanoparticles (SeNPs) have exclusive properties and bioactivities as compared to traditional selenium supplements. Therefore, SeNPs have been attracted worldwide interest as a therapeutic agent and food additive. In this review, we have discussed the therapeutics applications of selenium nanoparticles.
\end{abstract}

\section{Introduction}

Nanoparticles (NPs) are the submicroscopic particles with size range in between 1- $100 \mathrm{~nm}$ possessing peculiar properties such as small size, large surface area, surface chemistry, surface charge, multi-functionality, and solubility. They have played a considerable role in the drug delivery system, therapeutics, disease pathophysiology, and treatment privilege [1]. NPs have theproperty ofboosting the therapeutic potential of ionized drugs and also enhance the invasion of water-soluble compounds, vaccines, DNA, proteins, peptides, miRNA, siRNA, and more biological therapeutics [2]. The inorganic nanoparticles of $\mathrm{Ti}$, $\mathrm{Se}, \mathrm{Zn}, \mathrm{Ag}, \mathrm{Ce}, \mathrm{Au}$, and Fe play essential roles as theranostic agents and carriers for proteins, chemotherapeutic agents, etc. Among them, selenium nanoparticles attract more attention because of its high bioavailability and lower toxicity [3,4]. Selenium (Se) belongs to Group-6 in the periodic table with atomic number 34 . It is a semi solid-metal and present in $2+$, $4^{+}, 6+$, and $2-$ oxidation states. Se with zero oxidation state $\left(\mathrm{Se}^{0}\right)$ is a colorless, non-toxic, biologically inert material [5]. Selenium is present as selenocysteine in 25 human proteins and enzymes and plays a protective role in several disease conditions, e.g., hypercholesterolemia, some cancers, and cardiovascular disorders [6]. Selenium is a cofactor for thioredoxin reductases, and glutathione peroxidases and have exceptional growth modulating properties [7]. The biological activity of SeNPs depends on its size: smaller the particle, more significant is the activity [8]. SeNPs are used as antimicrobial, anti-tumor (both in vitro and in vivo), anticancer, and nutritional supplements $[9,10]$. SeNPs can be synthesized via physical techniques such as UV radiation and laser ablation; chemically via acid decomposition, catalytic reductions, and precipitation, biologically via microorganisms or plant extracts [11]. The health benefits of SeNPs are anti-aging, antioxidant, antidiabetic, boost immunity, reduces inflammation, improves fertility and brain functions, anti-asthma, anti-arthritic, treats muscular dystrophy, antiviral, and regulates thyroid [12].

\section{Role of SeNPS as antioxidant}

SeNPs possess the antioxidant capability due to selenoenzymes present in the Glutathione Peroxidase (GPXs), Thioredoxin Reductase (TR) and Iodothyronine Deiodinases (IDD). They are less toxic, more productive, and increase the activity of selenoenzymes (for combating oxidative stress) as compared to selenocysteine, Se-methyl, selenomethionine, and selenite [13]. SeNPs scavenge ROS, such as superoxide anion $\left(\mathrm{O}_{2}^{-}\right), 1,1$-diphenyl-2-picrylhydrazyl, singlet oxygen $\left({ }^{1} \mathrm{O}_{2}\right)$, and carbon-centered free radicals [14]. Zhang, et al. (2007) have been reported that the activity of glutathione peroxidase (GPx) in the liver of weanling pigs significantly becomes higher when the animals were administered Nano-Se diet (concentration range of 0.50 and $1.0 \mathrm{mg}$ Se. $\mathrm{kg}-1$ ) as compared to an inorganic form of selenium [15]. In another study, it has been observed that the administration of nanoselenium (10-20nm) 
Ameliorated acetaminophen (APAP)- induced liver damage in the rats and restored the cellular structure [16]. Similarly, the SeNPs have been shown a protective effect against $\mathrm{K}_{2} \mathrm{Cr}_{2} \mathrm{O}$ induced oxidative stress in some thyroid gland by preventing cell damage and found to restore the levels of catalase, GSH, superoxide dismutase, $\mathrm{T} 3, \mathrm{~T} 4 \mathrm{in}$ the treated animals [1].

\section{Role of SeNPS as an anticancer agent}

The anticancerous property of SeNPs is due to the induction of glutathione S-transferase (GST) by selenium [4]. SeNPs mitigates the problems of drug resistance and toxicities connected with chemotherapeutic agents. SeNPs have the potential to suppress the growth of cancer cells via the induction of cell cycle arrest at S phase [17]. Cancer cells selectively incorporate SeNPs via endocytosis, and then these SeNPs induces the apoptosis of cancer cell by triggering apoptotic signal transduction pathways [18]. SeNPs have been observed to inhibit the growth of prostate LNCaP cancer cells moderately via caspases mediated apoptosis in vitro [19]. Furthermore, it has been observed that SeNPs, along with Lactobacillus Brevis, stimulates the immune response via enhancing the production of interferon and delayed-type hypersensitivity response in a metastatic breast cancer mice model [20]. Sonkusre, et al. [2014] have shown that introduction of biologically synthesized SeNPs (concentration as low as $2 \mu \mathrm{g}$ Se. $\mathrm{mL}^{-1}$ ) are competent enough to suppress the proliferation and induce caspase-independent necrosis in human prostate adenocarcinoma cells (PC3). In addition to their anticancer potential alone, SeNPs when used in combination with 5 -Flourouracil ( $5-\mathrm{FU}$ ) has been shown to enhanced the anticancer potential of the drug in A375 human melanoma cells. The Figure 1 demonstrates the mode of SeNPs action as an potential anticancer agent and carrying out the apoptosis.

\section{Role of SeNPs in drug delivery}

SeNPs have been used as a drug delivery system for anticancer drugs/agents, for active immunization via carrying antigens and also for genes to the appropriate site [1]. The selective/ effective uptake and drug accumulation at the target site are possible because of the nanosize of these particles. SeNPs have been found to deliver siRNA against specific oncogenic gene [22] Yang, et al. have been observed that the usage of several surface decorators increases the cellular uptake and anticancer potential of nanoparticles. In their study, they functionalized SeNPs with Spirulina polysaccharides (SPS). They found that SPS surface decoration markedly increased the cellular uptake and cytotoxicity of SeNPs against various cancer cell lines. The SPS-SeNPs was observed to suppress the growth of cancer cell via apoptosis, as manifested by an increment of the sub-G1 cell population, fragmentation of DNA, condensation of chromatin, and translocation of phosphatidylserine [23]. Zheng, et al. (2015) have been reported that polyamidoamine dendrimermodified SeNPs efficiently deliver the siRNA and cisplatin to A549/DDP cells for reversal multidrug resistance. This combination induces apoptosis of cells via PI3K/Akt/mTOR and MAPK/ERK pathways in A549/DDP cells [24].

Furthermore, the mesoporous SeNPs has proven to be as a carrier for the delivery of doxorubicin for targeting breast cancer with lesser toxicity and improved anticancer potential [25]. Xia, et al. (2017) have reported that the delivery of siRNA using RGDfC-conjugated functionalized SeNPs is successful against liver carcinoma. It activates $\mathrm{Wnt} / \beta$-catenin signaling and sparks Bcl-2 mediated apoptosis [26]. The Figure 2 illustrates the modification of SeNPs and using them as a source of drug delivery.

\section{Role of SeNPS in reducing inflammation}

Inflammation is the earliest step in the onset of a disease/ injury leading to accretion of body fluids, white blood cells and release of prostaglandins and several inflammatory mediators [28]. Se helps in decreasing the inflammatory responses

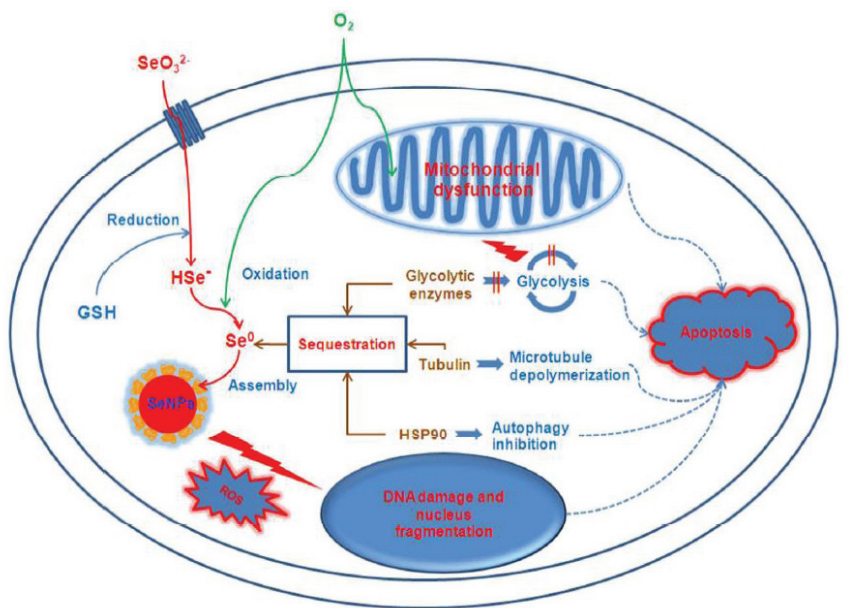

Figure 1: The mechanism of SeNPs as an anticancer agent [adapted from Bao, et al. 2015 [21]].

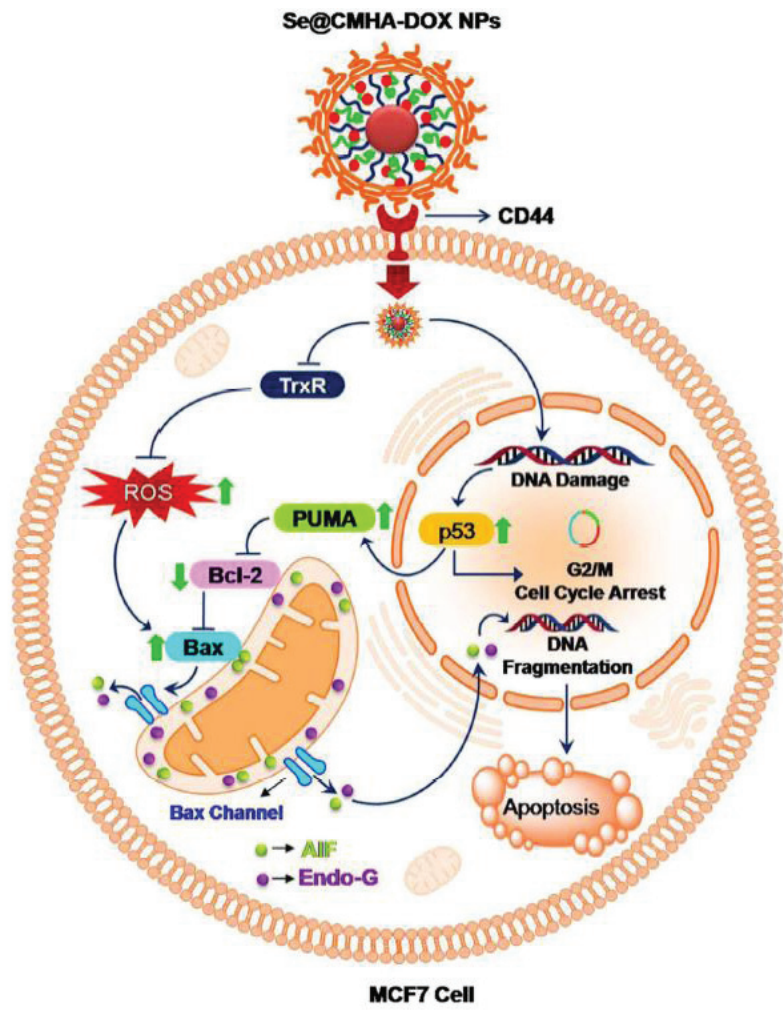

Figure 2: Role of SeNPs in the drug delivery [adapted from purohit, et al. 2017 [27]].

Citation: Jolly J, Rauf MA, Ahmad Z (2020) Selenium nanoparticles: Small is the new big: Mini review. Open Journal of Chemistry 6(1): 013-016. DOI: https://dx.doi.org/10.17352/ojc.000018 
in autoimmune/inflammatory diseases by increasing the antioxidant function of selenoproteins thus leading to decrease in the expression of many proinflammatory cytokines such as IL-6 and TNF alpha [29]. It has been observed that SeNPs decorated with Ulva lactuca polysaccharide sigficantly inhibited the proinflammatory cytokines (IL-6 and TNF- $\alpha$ ) and $\mathrm{NF}_{\kappa} \mathrm{B}$ signalling in dextran sodium sulphate induced colitis [30]. Similarly, it has been recently found that SeNPs decreases the expression of genes of pro inflammatory mediators like TNF- $\alpha$, PGE2 and TBAR in inflammation induced irradiated rats [31]. Combined treatment of melatonin-SeNPs have been shown to reduce the pathological abnormalities in liver, proinflammatory cytokines, proliferation of splenocyte, and levels of serum ALT, AST, NO, MDA in immunological liver injury induced by BCG and LPS in mice. Further, the combination also enhanced the activities of SOD and GPX thus decreasing the oxidative stress and inflammation [32].

\section{Role of SeNPS as antimicrobial}

SeNPs possess the antimicrobial activity thus inhibiting the growth of microbes such as bacteria, fungi, and viruses. Biologically synthesized SeNPs (from bacterium Ralstonia eutropha) has been showed to possess antimicrobial activity at a concentration of $100,100,250$, and $100 \mu \mathrm{g} / \mathrm{mL}$ by inhibiting 99\% growth of Pseudomonas aeruginosa, Staphylococcus aureus, Escherichia coli, and Streptococcus pyogenes respectively. Furthermore, it has been observed that SeNPs at a concentration of $500 \mu \mathrm{g} / \mathrm{mL}$ inhibits the growth of pathogenic fungi Aspergillus clavatus [33]. It has been reported that selenium dioxide treated probiotics that is Lactobacillus plantarum and Lactobacillus johnsonii or their cell-free spent stock inhibits the growth of $C$. albicans thus demonstrating their antifungal activity [34]. The antiviral activity of SeNPs has been investigated on H1N1 influenza virus and was found that the combined use of oseltamivir and amantadine-loaded SeNPs strongly inhibits the generation of ROS and activation of p53 phosphorylation and AKT [35-37].

\section{Conclusion}

Selenium is an essential trace element participating in many physiological processes of the organism and possesses tremendous pharmacological activities. Nanoparticles of Se are more productive and more appropriate for supplementation. Se NPs have low toxicity and high bioavailability, due to which they are used in various therapeutic applications such as drug delivery system, as anticancer drugs, as an antioxidant, against drug-induced toxicities, as anti-inflammatory and antidiabetic. The future aftermaths of SeNPs seem to be very favorable in enhancing the potency of existing treatments and the development of new therapies/remedies.

\section{References}

1. Khurana A, Tekula S, Aslam Saifi M, Venkatesh P, Godugu C (2019) Therapeutic applications of selenium nanoparticles. Biomed Pharmacother 111: 802-812. Link: https://bit.ly/2E0VOO9

2. Sperling RA, Parak WJ (2010) Surface modification, functionalization and bioconjugation of colloidal inorganic nanoparticles. Philos Trans R Soc Lond A: Math Phys Eng Sci 368: 1333-1383. Link: https://bit.ly/2ZODrEO
3. Kim T, Hyeon T (2014) Applications of inorganic nanoparticles as therapeutic agents. Nanotechnology 25: 012001. Link: https://bit.ly/39hElfP

4. Wang $\mathrm{H}$, Zhang J, Yu H (2007) Elemental selenium at nano size possesses lower toxicity without compromising the fundamental effect on selenoenzymes: comparison with selenomethionine in mice. Free Radic Biol Med 42: 1524-1533. Link: https://bit.ly/2CPLqsa

5. Weeks ME (1932) The discovery of the elements. VI. Tellurium and selenium J Chem Educ 9: 474. Link: https://bit.ly/3eOHGV5

6. Bai K, Hong B, He J, Hong Z, Tan R (2017) Preparation and antioxidant properties of selenium nanoparticles-loaded chitosan microspheres. Int $\mathrm{J}$ Nanomedicine 12: 4527-4539. Link: https://bit.ly/3jowYrN

7. WJ K, Ronan P, Michal T (2016) Biological activity of selenium: Revisited. IUBMB Life 68: 97-105. Link: https://bit.ly/2ZLVrPV

8. Torres SK, Campos VL, León CG, Rodríguez-Llamazares SM, Rojas SM, et al (2012) Biosynthesis of selenium nanoparticles by Pantoea agglomerans and their antioxidant activity. J Nanopart Res 14: 1236. Link: https://bit.ly/2CSa77

9. Tran PA, Webster TJ (2011) Selenium nanoparticles inhibit Staphylococcus aureus growth. Int J Nanomedicine 6: 1553-1558. Link: https://bit.ly/20Gol8f

10. Yazdi MH, Mahdavi M, Varastehmoradi B, Faramarzi MA, Shahverdi AR (2012) The immunostimulatory effect of biogenic selenium nanoparticles on the 4T1 breast cancer model: an in vivo study. Biol Trace Elem Res 149: 22-28. Link: https://bit.ly/3elosXj

11. Wadhwani SA, Shedbalkar UU, Singh R, Chopade BA (2016) Biogenic selenium nanoparticles: current status and future prospects. Appl Microbiol Biotechnol 100: 2555-2566. Link: https://bit.ly/2Cx1Rtt

12. Majeed W, Zafar M, Bhatti A, John P (2018) Therapeutic Potential of Selenium Nanoparticles. J Nanomed Nanotechnol 9:1. Link: https://bit.ly/3eMj4Mw

13. Kondaparthi P, Flora SJS, Naqvi S (2019) Selenium nanoparticles: An insight on its Pro-oxidant and antioxidant properties. Front Nanosci Nanotech 6: 1-5. Link: https://bit.ly/2BgConq

14. Kumar A, Suranjit Prasad K (2020) Biogenic selenium nanoparticles for their therapeutic application. Asian J Pharm Clin Res 13: 4-9. Link: https://bit.ly/3jreG9t

15. Zhang $\mathrm{H}, \mathrm{Xia} M, \mathrm{Hu} C$ (2007) Effect of nano-selenium on the activities of glutathione peroxidase and type-I deiodinase in the liver of weanling pigs. Sheng Wu Yi Xue Gong Cheng Xue Za Zhi 24: 153-156. Link: https://bit.ly/3hxtvWj

16. Amin KA, Hashem KS, Alshehri FS, Awad ST, Hassan MS (2016) Antioxidant and hepatoprotective efficiency of selenium nanoparticles against acetaminophen-induced hepatic damage. Biol Trace Elem Res 175: 136-145. Link: https://bit.ly/2E4qmi8

17. Luo $H$, Wang F, Bai $Y$, Chen $T$, Zheng W (2012) Selenium nanoparticles inhibit the growth of HeLa and MDA-MB-231 cells through induction of $S$ phase arrest. Colloids Surf B Biointerfaces 94: 304-308. Link: https://bit.ly/3joyDxx

18. Hosnedlova B, Kepinska M, Skalickova S, Fernandez C, Ruttkay-Nedecky B, et al. (2018) Nano-selenium and its nanomedicine applications: a critical review. Int J Nanomedicine 13: 2107-2128. Link: https://bit.ly/3fScfdK

19. Kong L, Yuan Q, Zhu H, Li Y, Guo Q, et al. (2011) The suppression of prostate LNCaP cancer cells growth by Selenium nanoparticles through Akt/Mdm2/AR controlled apoptosis. Biomaterials 32: 6515-6522. Link: https://bit.ly/2CSbhzG

20. Yazdi MH, Mahdavi M, Kheradmand E, Shahverdi AR (2012) The preventive oral supplementation of a selenium nanoparticle-enriched probiotic increases the immune response and lifespan of $4 \mathrm{~T} 1$ breast cancer bearing mice. Arzneimittelforschung 62: 525-531. Link: https://bit.ly/3fNWZ1y

Citation: Jolly J, Rauf MA, Ahmad Z (2020) Selenium nanoparticles: Small is the new big: Mini review. Open Journal of Chemistry 6(1): 013-016. 
21. Bao P, Chen Z, Tai RZ, Shen HM, Martin FL, et al. (2015) SeleniteInduced Toxicity in Cancer Cells Is Mediated by Metabolic Generation of Endogenous Selenium Nanoparticles. J Proteome Res 14: 1127-1136. Link: https://bit.ly/2ZK3nkQ

22. Sonkusre $P$, Nanduri R, Gupta $P$, Cameotra SS (2014) Improved extraction of intracellular biogenic selenium nanoparticles and their specificity for cancer chemoprevention. J Nanomed Nanotechnol 5: 2. Link: https://bit.ly/3eOJ61R

23. Li Y, Lin Z, Zhao M, Xu T, Wang $H$, et al. (2016) Multifunctional selenium nanoparticles as carriers of HSP70 siRNA to induce apoptosis of HepG2 cells Int J Nanomedicine 11: 3065-3076. Link: https://bit.ly/39mWqte

24. Yang $F$, Tang Q, Zhong $X$, Bai $Y$, Chen $T$, et al. (2012) Surface decoration by Spirulina polysaccharide enhances the cellular uptake and anticancer efficacy of selenium nanoparticles. Int $\mathrm{J}$ Nanomedicine 7: 835-844. Link: https://bit.ly/30AYrOe

25. Zheng W, Cao C, Liu Y, Yu Q, Zheng C, et al. (2015) Multifunctional polyamidoamine-modified selenium nanoparticles dual-delivering siRNA and cisplatin to A549/DDP cells for reversal multidrug resistance. Acta Biomater 11: 368-380. Link: https://bit.ly/3fQu4K4

26. Zhao S, Yu Q, Pan J, Zhou Y, Cao C, et al. (2017) Redox-responsive mesoporous selenium delivery of doxorubicin targets MCF-7 cells and synergistically enhances its anti-tumor activity, Acta Biomater 54: 294-306. Link: https://bit.ly/2ZMc5yY

27. Purohit MP, Verma NK, Kar AK, Singh A, Ghosh D, et al. (2017) Inhibition of Thioredoxin Reductase by Targeted Selenopolymeric Nanocarriers Synergizes the Therapeutic Efficacy of Doxorubicin in MCF7 Human Breast Cancer Cells. ACS Applied Materials Interfaces 9: 36493-36512. Link: https://bit.ly/2CA1DIf

28. Xia Y, Lin Z, Li Y, Zhao M, Wang C, et al. (2017) Targeted delivery of siRNA using RGDfC-conjugated functionalized selenium nanoparticles for anticancer therapy. J Mater Chem B 5: 6941-6952. Link: https://rsc.li/2CALImG
29. Ricciotti E, FitzGerald GA (2011) Prostaglandins and inflammation. Arterioscler Thromb Vasc Biol 31: 986-1000. Link: https://bit.ly/2ZJZvAm

30. Duntas LH (2009) Selenium and inflammation: underlying anti-inflammatory mechanisms. Horm Metab Res 41: 443-447. Link: https://bit.ly/3hokGhs

31. Zhu C, Zhang S, Song C, Zhang Y, Ling Q, et al. (2017) Selenium nanoparticles decorated with Ulva lactuca polysaccharide potentially attenuate colitis by inhibiting NF-kB mediated hyper inflammation. J Nanobiotechnol 15: 20. Link: Link: https://bit.ly/30zynmP

32. El-Ghazaly MA, Fadel N, Rashed E, El-Batal A, Kenawy S (2016) Antiinflammatory effect of selenium nanoparticles on the inflammation induced in irradiated rats. Can J Physiol Pharmacol 95: 101-110. Link: https://bit.ly/3eHUUTq

33. Wang H, Wei W, Zhang SY, Shen YX, Yue L, et al. (2005) Melatonin-selenium nanoparticles inhibit oxidative stress and protect against hepatic injury induced by Bacillus Calmette-Guérin/lipopolysaccharide in mice. J Pineal Res 39: 156-163. Link: https://bit.ly/2ZMLt0T

34. Srivastava N, Mukhopadhyay M (2015) Green synthesis and structura characterization of selenium nanoparticles and assessment of their antimicrobial property. Bioprocess Biosyst Eng 38: 1723-1730. Link: https://bit.ly/2CnPW1e

35. Kheradmand E, Rafii F, Yazdi MH, Sepahi AA, Shahverdi AR, et al. (2014) The antimicrobial effects of selenium nanoparticle-enriched probiotics and their fermented broth against Candida albicans. Daru 22: 1-6. Link: https://bit.ly/2CWsF6s

36. Li Y, Lin Z, Guo M, Xia Y, Zhao M, et al. (2017) Inhibitory activity of selenium nanoparticles functionalized with oseltamivir on H1N1 influenza virus. Int $J$ Nanomedicine 12: 5733-5743. Link: https://bit.ly/2ZJYI7P

37. Li Y, Lin Z, Guo M, Zhao M, Xia Y, et al. (2018) Inhibition of H1N1 influenza virus induced apoptosis by functionalized selenium nanoparticles with amantadine through ROS-mediated AKT signaling pathways. Int J Nanomedicine 13: 20052016. Link: https://bit.ly/2BfXClk

\section{Discover a bigger Impact and Visibility of your article publication with}

\section{Peertechz Publications}

Highlights

* Signatory publisher of ORCID

* Signatory Publisher of DORA (San Francisco Declaration on Research Assessment)

* Articles archived in worlds' renowned service providers such as Portico, CNKI, AGRIS, TDNet, Base (Bielefeld University Library), CrossRef, Scilit, J-Gate etc.

* Journals indexed in ICMJE, SHERPA/ROMEO, Google Scholar etc.

- OAI-PMH (Open Archives Initiative Protocol for Metadata Harvesting)

* Dedicated Editorial Board for every journal

* Accurate and rapid peer-review process

* Increased citations of published articles through promotions

* Reduced timeline for article publication

Submit your articles and experience a new surge in publication services (https://www.peertechz.com/submission).

Peertechz journals wishes everlasting success in your every endeavours.

Copyright: @ 2020 Jolly J, et al. This is an open-access article distributed under the terms of the Creative Commons Attribution License, which permits unrestricted use distribution, and reproduction in any medium, provided the original author and source are credited.

Citation: Jolly J, Rauf MA, Ahmad Z (2020) Selenium nanoparticles: Small is the new big: Mini review. Open Journal of Chemistry 6(1): 013-016. 